\title{
057 INNOVATIVE SPENDING IN HEALTH: WHAT SHOULD MONEY BE SPENT ON TO MAKE GLOBAL HEALTH INNOVATIONS MORE EFFECTIVE IN DEVELOPING COUNTRIES?
}

Julius T Mugwagwa. The Open University, Milton Keynes, United Kingdom

\subsection{6/bmjopen-2015-forum2015abstracts.57}

Background Delivering effective healthcare to people in developing countries is a perennial challenge, hence the unending search for, and implementation of creative or innovative ways of spending money and other resources that are available for health.

Objectives This paper presents and discusses some innovations in health-spending from South Africa and Zimbabwe. The presentation will also ask a number of inter-related theory, policy and practice questions, among others, how such innovations get embedded in health systems, how they can be/are cushioned from internal and external shocks, whether there are any back-up mechanisms, and who is liable when such innovations fail?

Methods This paper is based on an on-going three-year project and is drawing on evidence emerging from interviews with key stakeholders located at various points within and around health systems in South Africa and Zimbabwe, observations and document reviews.

Result From creation of policy and practice space for medical facilities run separately or collectively by public, private and civil society stakeholders; generation, consolidation and use of disease surveillance data at district, provincial and national levels; to empowering rural communities in shaping health delivery options, there is abundant evidence in the two countries of innovative efforts to do more with less.

Conclusion This paper confirms the need for agile and innovative approaches to ensuring that the health needs of marginalised populations are met. In addition to reflecting on the utility and effectiveness of some approaches already in use, the paper also brings to the fore some hitherto unreported innovations in health spending in South Africa and Zimbabwe. 